\title{
Phenological shifts in hatch timing of northern shrimp Pandalus borealis
}

\author{
R. Anne Richards* \\ NOAA Northeast Fisheries Science Center, Woods Hole, Massachusetts 02543, USA
}

\begin{abstract}
The northern shrimp Pandalus borealis reaches the southern limit of its distribution in the Gulf of Maine, USA. Previous studies have revealed geographic clines in northern shrimp population parameters (growth, maturity, longevity) which co-vary with environmental temperature, and laboratory studies have confirmed temperature effects. In this study, field data were used to investigate reproductive phenology of northern shrimp in the Gulf of Maine during 1980 to 2011 in relation to ocean temperatures. Timing of the annual shrimp hatch was estimated by sampling commercial catches during the brooding and hatching period. Hatch timing metrics were regressed against composite environmental variables derived from principal component analysis of sea surface temperature and bottom temperature anomalies. Shrimp population indices (spawner abundance and mean size) were included as covariates. Shifts have occurred in timing of hatch initiation (earlier) and completion (later), with the overall result of a longer hatch period in recent years. The midpoint of the hatch period has varied without trend. All hatch timing metrics were significantly related to temperature variables, several of which have warmed significantly during the study period. In the short term, phenological shifts in hatch timing of northern shrimp may be beneficial because they effectively increase the window of opportunity for larvae to encounter good survival conditions. The continued warming predicted for the Gulf of Maine will likely produce further changes, some of which may be in unexpected directions.
\end{abstract}

KEY WORDS: Phenology - Reproduction - Climate change - Decapod crustacean - Shrimp · Temperature $\cdot$ Gulf of Maine

Resale or republication not permitted without written consent of the publisher

\section{INTRODUCTION}

The critical role of phenology in structuring communities and ecosystems has become well-recognized as climate change manifests itself in terrestrial and aquatic systems (Edwards \& Richardson 2004, Parmesan 2006, Sydeman \& Bograd 2009). Phenology refers to the timing of life history events with respect to the environment. Examples include timing of leaf emergence, phytoplankton blooms, seasonal migrations, and reproduction, processes which are strongly influenced by environmental cues such as temperature and day length. Climate change may lead to community reorganization if species respond differently to changing temperature cues, thus lead- ing to mis-matches in the population trajectories of inter-dependent species (e.g. predators and prey). Phenological shifts are likely to be important not only for persistence of individual species, but for trophic dynamics, community structure, and stability of ecosystems.

The present study examines the influence of temperature on hatch timing of a commercially and ecologically important marine invertebrate, the northern shrimp Pandalus borealis. The northern shrimp is an important food source for commercially important fish species (Link \& Idoine 2009), and is itself the target of commercial fisheries throughout its circumboreal distribution in the North Atlantic Ocean (Bergström 2000). Inter-population comparisons and 
rearing experiments have shown that temperature is an important structuring force in the life history of northern shrimp. For example, individual growth rates decrease and longevity increases with increasing latitude, and reproductive timing can be manipulated in the laboratory using temperature (reviewed by Shumway et al. 1985, Bergström 2000).

The present study examined changes in reproductive phenology of the southern-most population of northern shrimp. This population is concentrated in the western Gulf of Maine, USA, where bottom temperature remains colder during summer than in the eastern Gulf of Maine (Haynes \& Wigley 1969, Mountain \& Jessen 1987). Temperature is thought to have an important influence on northern shrimp population dynamics in this region (Dow 1964, Apollonio et al. 1986), and recent studies have demonstrated a significant relationship between temperature and recruitment, with higher recruitment in colder years (Richards et al. 1996, in press). Paradoxically, unusually high recruitment has been observed in some recent years (Hunter et al. 2011, Richards et al. in press) despite an overall warming trend in the western Gulf of Maine (Friedland \& Hare 2007).

Northern shrimp are protandrous sequential hermaphrodites, reproducing annually in the Gulf of Maine as males at Age 2 and as females at Ages 4 and 5, after which most apparently die (Shumway et al. 1985, Clark et al. 2000). Eggs are spawned in late summer/early fall following a nuptial molt, and the fertilized eggs are carried for several months, attached to setae on the female's pleopods. In late fall/early winter, females begin to migrate inshore in preparation for the larval hatch, which occurs in near-shore waters $(<50 \mathrm{~m})$ during late winter/early spring (Haynes \& Wigley 1969, Shumway et al. 1985, Bergström 2000). Females return to deeper water after hatching their brood and are thought to undergo 2 to 4 molts before reproducing the following year as second-year females (Shumway et al. 1985).

\section{MATERIALS AND METHODS}

\section{Hatch date estimation}

Data from biological sampling of commercial shrimp catches in the Gulf of Maine (Fig. 1) collected by the Maine Department of Marine Resources were used to estimate the timing of the shrimp hatch for 1980 to 1983 and 1989 to 2011 (no data were available for 1984 to 1988). The fishery targets females when they move inshore during winter and generally spans the period of hatching. Samples were collected according to a proportional sampling scheme, thus ports handling the greatest volume of shrimp were the most heavily sampled. Changes over time in the proportion of egg-bearing females were used to estimate the period of hatching for each year. All northern shrimp are mature in their first year as females (Shumway et al. 1985); therefore, females not bearing eggs were presumed to have already hatched their eggs. Stage I females, identified by pronounced sternal spines (McCrary 1971), were excluded because they would have been newly transformed from males. Probit analysis of the proportion of reproductive females whose eggs had hatched was used to define metrics of hatch timing (Proc Probit, SAS Institute 2003). The metrics were hatch initiation, defined as the day of year (DOY) on which $10 \%$ of females had hatched their brood, hatch midpoint

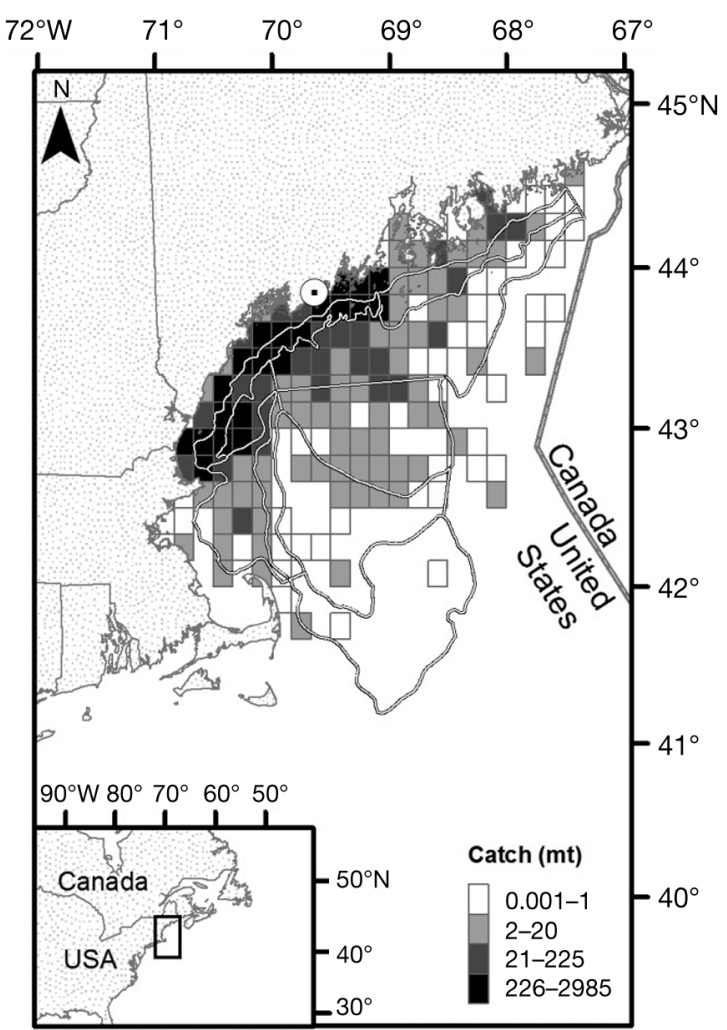

Fig. 1. Pandalus borealis. Distribution of northern shrimp catch during 2001 to 2010 in the western Gulf of Maine, USA, reported by 10 min squares (latitude, longitude). Circle indicates location of sampling for daily sea surface temperature at Boothbay Harbor, Maine. Lines indicate boundaries of survey strata used in the calculation of bottom temperature anomalies and coincide with late spring, summer, and early fall distribution of female northern shrimp. Inset shows the location of the study area in the northwest Atlantic Ocean 
(50\% hatched), hatch completion ( $90 \%$ hatched), and duration of the hatch period (number of days from initiation to completion). In years when the fishery ended before the hatch was complete (12 of 27 years), an assumed hatch completion date of 1 April (90th percentile of completion dates for the time series) was used to anchor the probit curve. For 1 year (2005), this assumption resulted in a poor fit of the logistic model, and an assumed hatch completion date was not imposed for that year.

\section{Temperature data}

Bottom temperature data came from shipboard hydrographic measurements taken during bottom trawl surveys conducted annually by the Northeast Fisheries Science Center (NEFSC). Approximately 40 stations were sampled in the western Gulf of Maine each spring and autumn according to a stratified random sampling design (Grosslein 1969, Smith 2002; Fig. 1). Bottom temperature measurements were made using expendable bathythermographs during 1979 to 1990 and with electronic profiling conductivity/temperature/ depth instruments thereafter. For each station, bottom temperature anomalies (BTAs) were estimated relative to a set of reference annual cycles for temperature at fixed locations during 1978 to 1987 (Holzwarth \& Mountain 1990).

Station anomalies were calculated as the difference between the observed value and the reference value for each station location and DOY. Station anomalies were averaged (stratified mean with stratum weight $=$ area of stratum in squared nautical miles, $\mathrm{n}$ miles $^{2}$ ) to derive an annual BTA value. This method compensates for variation in the timing of surveys from year to year to provide a consistent estimate of inter-annual temperature variability (Fig. 2E,F).

Sea surface temperature (SST) measured daily from a dock in mid-coast Maine (Boothbay Harbor, Fig. 1) was also used in the analysis (Fig. 2A-D;
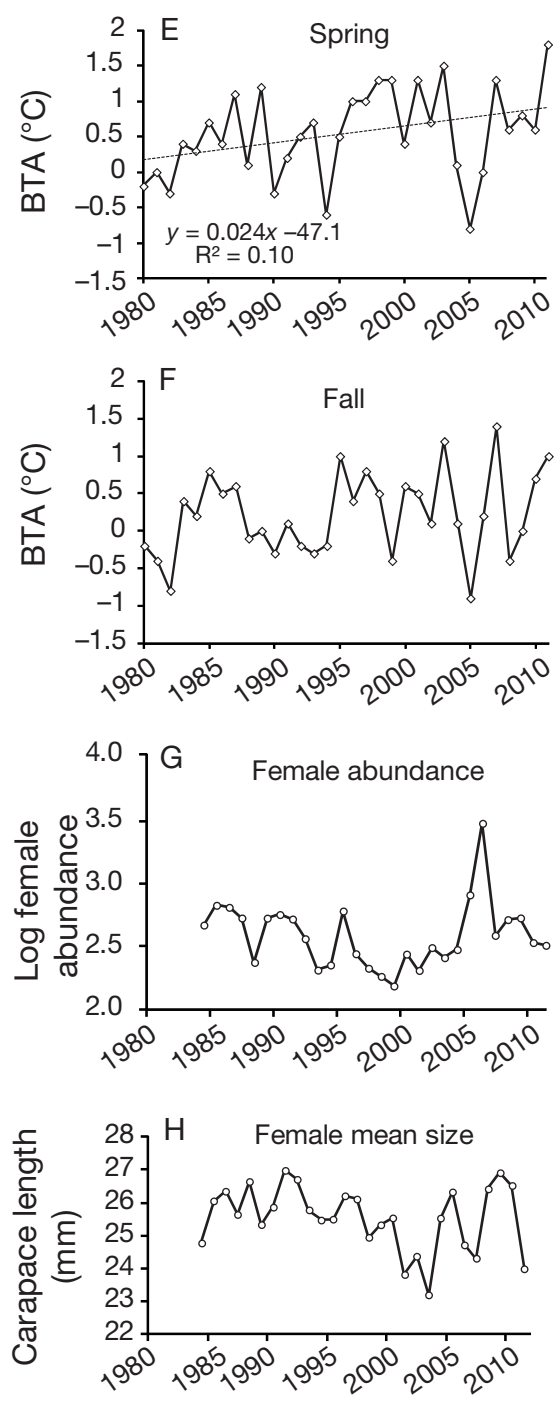

Hatch year

Fig. 2. Pandalus borealis. Trends in (A-D) sea surface temperature (SST) measured daily at Boothbay Harbor, Maine, USA, from 1980 to 2011; (E,F) bottom erature anomalies (BTA) in the western Gulf of Maine during 1980 to 2011; (G) northern shrimp spawner abundance index (log stratified geometric mean number per tow), 1984 to 2011; (H) northern shrimp spawner mean carapace length (mm), 1984 to 2011. Trend lines are included for series with significant trends; $\mathrm{r}^{2}$ values are adjusted for number of degrees of freedom each in model

www.maine.gov/dmr/rm/environmentaldata.html). The daily temperature data allowed examination of temperature trends during time periods approximating specific stages of shrimp oogenesis and embryonic development. Comparable fine-scale data were not available for bottom temperature; however, first differences of mean SST measured at Boothbay Harbor during spring (April to May) and fall (October to November) 1980 to 2011 were significantly correlated with first differences of the mean bottom temperature anomalies from the NEFSC spring and fall 
Table 1. Pandalus borealis. Time periods used to define developmental stanzas of northern shrimp. DOY: day of year

\begin{tabular}{|lcc|}
\hline Developmental stanza & Dates & DOY \\
\hline Oogenesis & 1 May-14 Sep & $120-257$ \\
Early embryogenesis & 15 Sep-30 Nov & $258-334$ \\
Late embryogenesis & 1 Dec-14 Jan & 335-365, 1-14 \\
Final maturation & 15 Jan-28 Feb & $15-59$ \\
\hline
\end{tabular}

surveys (spring $r=0.40, p<0.05$, fall $r=0.57, p<$ 0.001), indicating that the BTAs and SSTs followed similar trends over time. Mean daily SST was calculated for developmental stanzas defined in Table 1 (based on Haynes \& Wigley 1969).

Adjustments were made for leap years so that the same number of days was entered into the statistics for each year. Missing data for 14 days in mid-July 2004 were filled using the average SST during the $7 \mathrm{~d}$ before and after the gap.

\section{Population indices}

To account for possible effects of abundance and size of spawners on timing of the hatch, annual estimates of spawner abundance (geometric stratified mean number per tow) and stratified mean carapace length of spawners were included in the analysis (Hunter et al. 2011). These demographic indices were estimated using data from a standardized shrimp survey conducted during 1984 to 2011 by the Atlantic States Marine Fisheries Commission (Clark 1989, Clark et al. 2000). The indices were based on approximately 40 stations sampled annually in midsummer according to a stratified random design.

\section{Data analysis}

The analysis consisted of 2 parts: (1) testing for temporal trends in the environmental and biological time series and (2) relating the environmental and shrimp demographic variables to shrimp hatch timing metrics.

To test for significant trends over time, linear regression of each variable on year was used (Proc Reg, SAS Institute 2003) and the significance of the slope parameter examined. The model residuals were assessed for autocorrelation using the Durbin Watson $D$ statistic. If $D$ was significant, autoregressive error terms were included in the regression model (Proc Autoreg, SAS Institute 2003). The trend analysis of
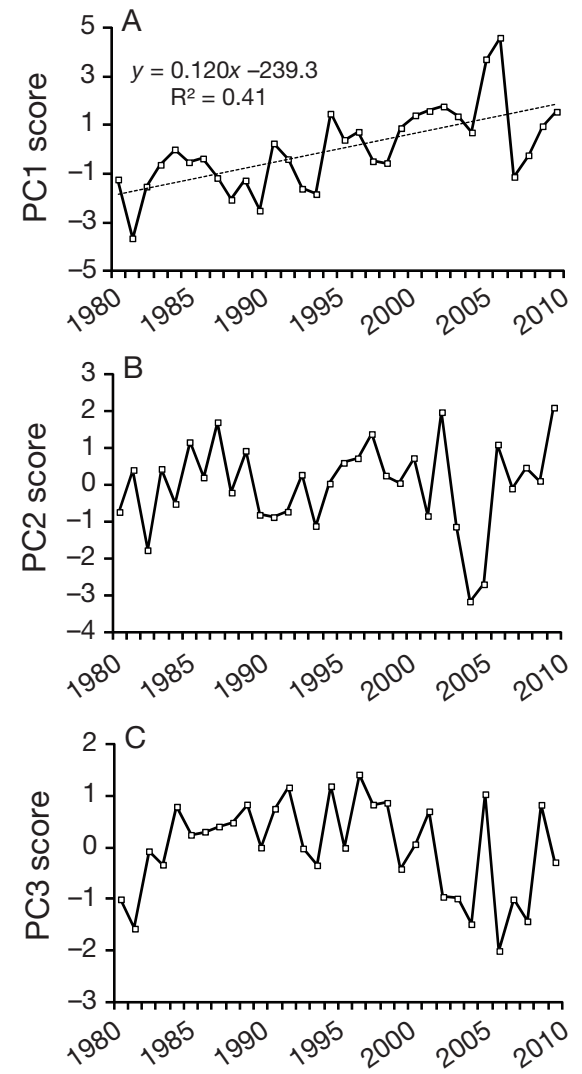

Fig. 3. PC scores from a principal component analysis of standardized temperature variables (spring and fall bottom temperature anomaly and sea surface temperature during stages of the reproductive cycle ), 1980 to 2011. (A) PC1, (B) $\mathrm{PC} 2,(\mathrm{C}) \mathrm{PC} 3$

the temperature time series included 1984 to 1988 , years for which hatch data were not available.

To examine the effects of temperature on hatch metrics, principal component (PC) scores from a principal component analysis (PCA) of standardized temperature variables (BTA and SST) were used to express the temperature trends (Fig. 3). Using the PCs avoided potential problems with collinearity in the temperature time series. The PCs were inputs to a multiple regression model relating hatch timing metrics to temperature, with abundance and size of spawners included as covariates (Fig. 2G,H). Models that included shrimp population indices were limited to 1989-2011 because the survey started in 1984, and hatch data were not available for 1984-1988. The regression model was:

$$
H_{i}=a+\sum^{j} \beta_{j} P C_{i j}+\gamma N_{i}+\delta L_{i}+\varepsilon
$$

where $H=$ hatch timing metric, $i=$ reproductive year (May-Feb), $a=$ intercept $, \beta, \gamma, \delta=$ regression coefficients, $P C=\mathrm{PC}$ score,$j=\mathrm{PC}$ number,$N=$ spawner 
abundance index (log stratified geometric mean number per tow), $L=$ mean length of spawners (stratified mean number per tow at length), and $\varepsilon=$ error. Terms were included in the model if they were significant at $\mathrm{p}<0.05$. The model residuals were assessed for autocorrelation using the Durbin Watson $D$ statistic.

\section{RESULTS}

The results of the probit analysis of proportion hatched over time are shown in Figs. $4 \& 5$. The derived hatch timing metrics were variable over time, particularly after the mid-1990s; however, hatch initiation and hatch completion showed significant trends with time (Fig. 5). Hatch initiation became earlier and hatch completion later, thus increasing the overall duration of the hatch period, which also had a significant time trend (Table 2, Fig. 5). The duration of the hatch period had a strong inverse relation to timing of hatch initiation, with earlier hatch initiation associated with longer hatch duration (Fig. 6E). In contrast, hatch midpoint did not show a significant trend during the study period. Hatch initiation ranged from DOY 10 to 56 (median DOY 36), hatch midpoint from DOY 39 to 79 (median DOY 57), and hatch completion from DOY 64 to 118 (median DOY 76). Median duration of the hatch period was $44 \mathrm{~d}$ (range 16 to $78 \mathrm{~d}$ ).

Analysis of temperature trends revealed significant increases during the study period in SST during oogenesis, early embryogenesis, and late embryogenesis, and in spring BTA (Table 2, Fig. 2). SST during final maturation and autumn BTA did not show significant trends over time (Table 2, Fig. 2). The models for trends in SST during oogenesis and early embryogenesis included a significant autoregressive error term at a lag of 1 ; autoregressive error terms at higher lags were not significant.

In the PCA of environmental variables, the first 3 PCs accounted for $84 \%$ of the variance (Table 3); therefore, higher-order PCs were dropped from subsequent analysis (Table 2). PC1 (49\% of variance) represented primarily SST during oogenesis, early embryogenesis, and late embryogenesis, PC2 (24\% of variance) was weighted most heavily on spring and autumn BTA, and PC3 (14\% of variance) on SST during final maturation and oogenesis. PC1 was the only PC that showed a significant time trend (Fig. 3).

Regardless of whether the hatch timing metrics showed a trend over time, all were significantly related to temperature PCs, and none was significantly related to shrimp demographic variables (spawner abundance and spawner mean length; Table 4, Fig. 6). Hatch initiation and hatch midpoint were negatively related to PC1 and hatch duration was positively related to PC1. Hatch midpoint and hatch completion were negatively related to PC3. None of the regression models had significant autoregressive error terms.

\section{DISCUSSION}

In the present study, significant relationships were found between temperature and 4 measures of hatch timing: hatch initiation, midpoint, and completion, and duration of the hatch period. Several of the tem- 

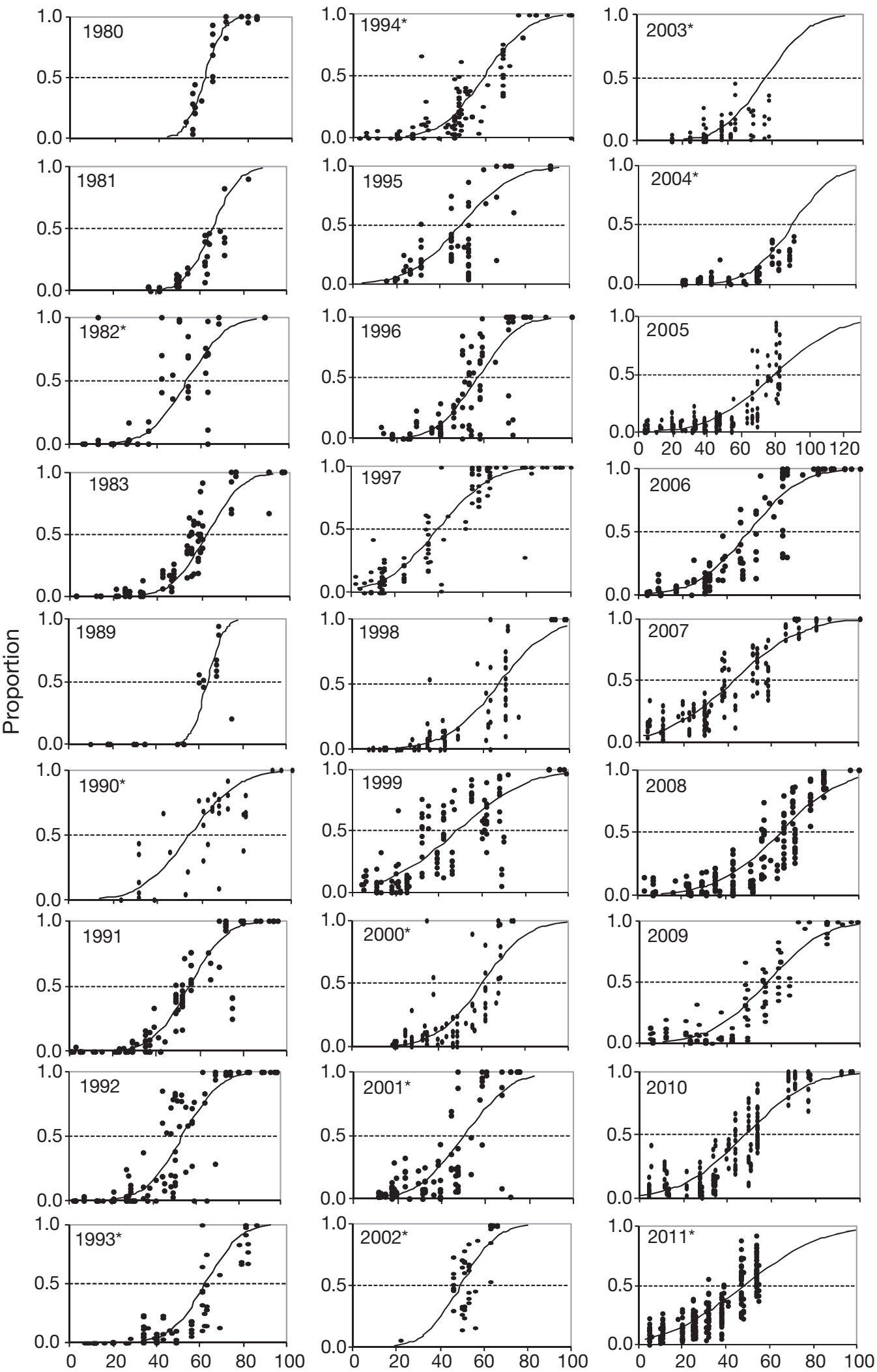

Day of year

Fig. 4. Pandalus borealis. Probit analysis of the proportion of mature females that had hatched their brood on each sampled day. Each point represents 1 sample from the shrimp fishery. Asterisks next to year label indicate curves that were estimated assuming $100 \%$ had hatched by 1 April. Note $x$-axis change in 2005 

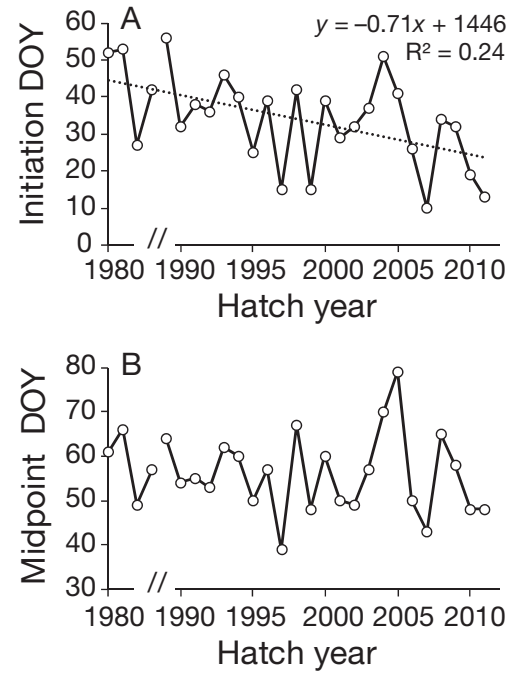

Fig. 5. Pandalus borealis. Day of year (DOY) of hatch (A) initiation, (B) midpoint, (C) completion, (D) duration estimated from probit analysis of the proportion of females whose embryos had hatched. (E) Relationship between hatch initiation and duration of hatch period
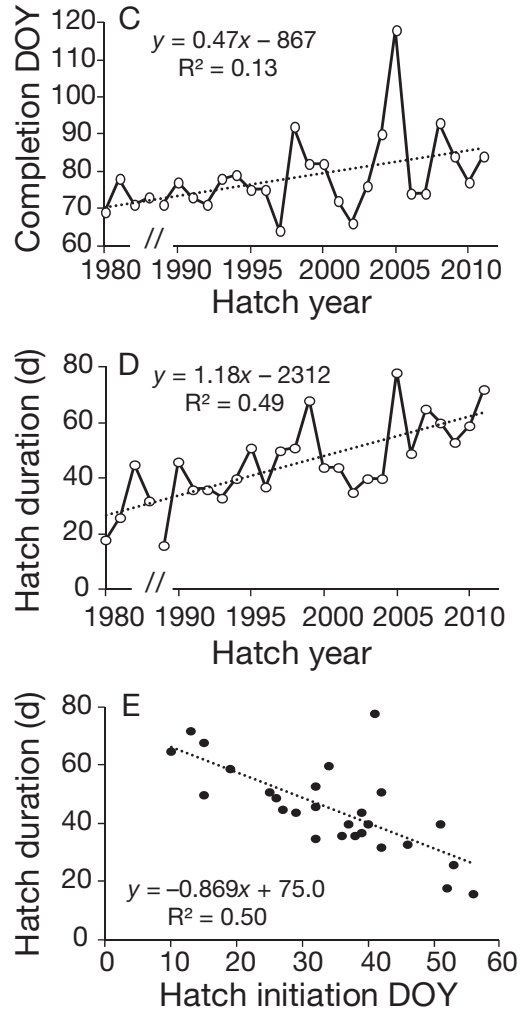

Table 3. Eigenvectors of the correlation matrix from principal component analysis (PCA) of temperature variables, 1980 to 2011. BTA: bottom temperature anomaly; SST: sea surface temperature

\begin{tabular}{|lrrrrrr|}
\hline & PC1 & PC2 & PC3 & PC4 & PC5 & PC6 \\
\hline Fall BTA & 0.356 & 0.554 & 0.123 & -0.495 & 0.472 & 0.288 \\
Spring BTA & 0.206 & 0.700 & 0.180 & 0.487 & -0.338 & -0.288 \\
Oogenesis SST & 0.484 & -0.094 & -0.478 & 0.423 & -0.046 & 0.589 \\
Early embryogenesis SST & 0.518 & -0.195 & -0.308 & 0.012 & 0.352 & -0.689 \\
Late embryogenesis SST & 0.490 & -0.189 & 0.165 & -0.477 & -0.685 & -0.009 \\
Final maturation SST & 0.296 & -0.346 & 0.776 & 0.333 & 0.260 & 0.113 \\
Eigenvalue & 2.944 & 1.451 & 0.837 & 0.416 & 0.264 & 0.087 \\
Proportion of variance & 0.491 & 0.242 & 0.140 & 0.069 & 0.044 & 0.015 \\
Cumulative proportion & 0.491 & 0.733 & 0.872 & 0.942 & 0.986 & 1.000 \\
\hline
\end{tabular}

Table 4. Pandalus borealis. Results of multiple regression of principal components (PCs; temperature data) on hatch timing with spawner abundance and spawner mean size as covariates. Only parameters significant at $p<0.05$ were included. Final models included all years for which hatch timing data were available (1980-1983, 1989-2011, $\mathrm{n}=27$ ). Model $\mathrm{r}^{2}$ values have been adjusted

for the number of degrees of freedom in each model. DOY: day of year

\begin{tabular}{|lll|}
\hline Dependent variable & Model & $\mathrm{r}^{2}$ \\
\hline Hatch initiation DOY & $y=-3.74(\mathrm{PC} 1)+34.69$ & $0.26^{* *}$ \\
Hatch midpoint DOY & $y=-1.89(\mathrm{PC} 1)-3.91(\mathrm{PC} 3)+56.23$ & $0.29^{* *}$ \\
Hatch completion DOY & $y=-4.72(\mathrm{PC} 3)+78.05$ & $0.15^{*}$ \\
Hatch duration $(\mathrm{d})$ & $y=3.54(\mathrm{PC} 1)+44.79$ & $0.14^{*}$ \\
\hline
\end{tabular}

perature variables showed significant warming trends during the study period, and these were associated with shifts in timing of hatch initiation (earlier) and completion (later), with an overall result of a longer hatch period in recent years.

Reproductive timing in marine invertebrates is a result of the interplay between genetically controlled endogenous cycles, exogenous cues that fine-tune the timing of the endogenous cycle to short-term conditions, and environmental factors that set physiological limits (Morgan 1995, Gelin et al. 2001, Nagaraju 2011). The most widely known exogenous cues in the marine environment relate to temperature, light-dark, and tidal/lunar cycles, the importance of which varies among species and habitats. For example, in deepwater shrimp Solenocera melantho residing in relatively constant temperatures, photoperiod is thought to provide an exogenous cue for reproductive timing (Ohtomi et al. 1998). In American lobsters Homarus americanus, both temperature and photoperiod (transition from shortening to lengthening day) regulate timing of spawning (Quackenbush 1994). In Crangon crangon, a shrimp that initiates oogenesis in brackish water, salinity is a key regulating factor (Gelin et al. 2001).

Effects of temperature on reproduction of crustaceans, including Pandalus borealis, have been examined widely in laboratory studies. These generally show strong inverse relations between temperature and developmental time of gonads, embryos, and larvae (Brillon et al. 2005, Webb et al. 2007, Roberts et al. 2012). However, few studies have demonstrated population-level temperature effects on reproduction from field data. Possible reasons range from insufficient monitoring data and/or lack of contrast in environmental temperatures, to the many 

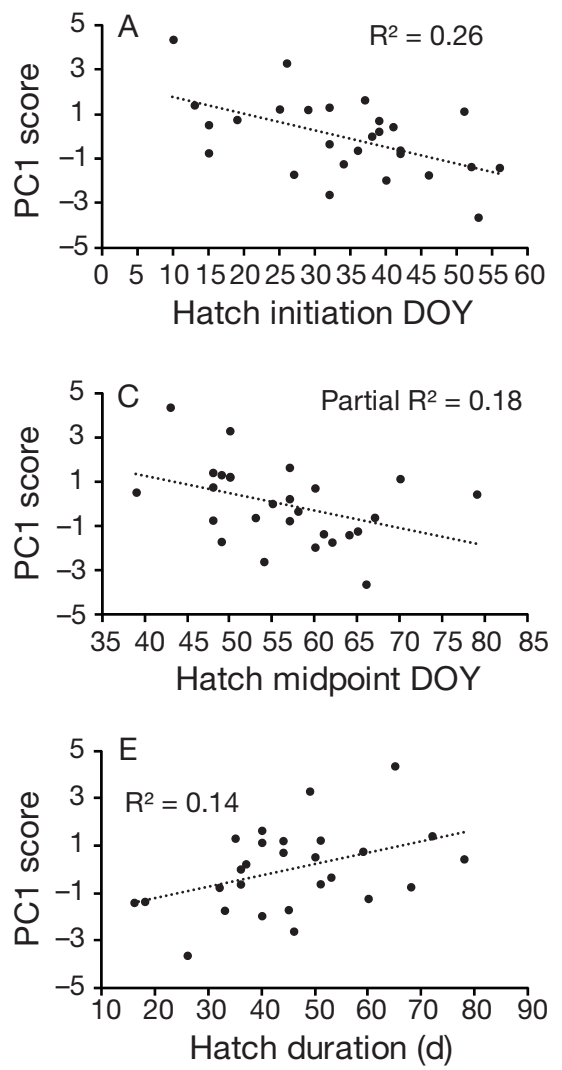
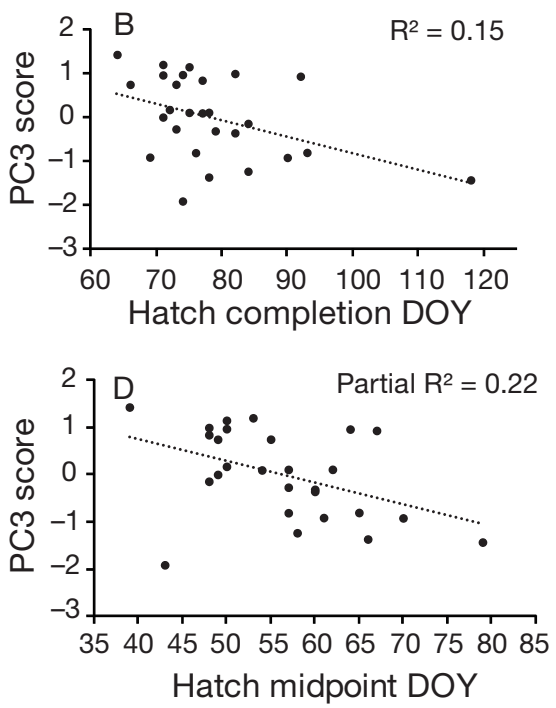

Fig. 6. Pandalus borealis. Relationships between shrimp hatch timing metrics, principal components (PCs; temperature), and shrimp population indices. (A) Hatch initiation, (B) hatch completion, $(\mathrm{C}, \mathrm{D})$ hatch midpoint, $(\mathrm{E})$ hatch duration. DOY: day of year
(Bergström 2000). These observations suggest that temperature is highly influential in reproduction of northern shrimp in the Gulf of Maine, as has been intimated by results from laboratory and localized field studies in this region (Stickney \& Perkins 1977, Shumway et al. 1985, Apollonio et al. 1986).

Demographic variables did not have significant effects on hatch timing in the present study. Laboratory studies have shown that size of spawning Pandalus borealis can affect timing of egg extrusion, with larger females spawning earlier (Nunes 1984); however, spawner size effects were not evident from the field data, nor were spawner abundance effects. The Gulf of Maine population of $P$. borealis has only 2 size/age classes in the spawning stock (other North Atlantic populations have up to 5; Shumway et al. 1985), and first-year females tend to dominate spawner abundance (Hunter et al. 2011). This may make uncontrolled factors that interact in complex ways in the field, potentially masking temperature or other univariate effects. Given that environmental conditions can be heterogeneous within the spatial extent of a population, only highly influential factors are likely to be identifiable at the population level.

Evidence for population-level temperature effects on reproduction of Pandalus borealis comes primarily from inter-population comparisons (Shumway et al. 1985, Bergström 2000, Wieland 2005, Koeller et al. 2009). A notable exception is a $4 \mathrm{yr}$ study in a Swedish fjord that was periodically isolated from a larger strait and became thermally homogeneous during periods of northern shrimp oogenesis. The study found a strong $\left(\mathrm{r}^{2}=0.95, \mathrm{n}=4\right)$ inverse relationship between ocean temperature and the duration of oogenesis (Bergström 1991). In the present study, relationships between temperature and hatch metrics were much less precise (Table 4, Fig. 6); however, the Gulf of Maine study area is large ( 12 $000 \mathrm{n}$ miles $^{2}$ ) and open, and conditions are likely far more variable than in an isolated fjord. The inter-annual range in BTAs and SSTs was relatively narrow in the present study $\left(\sim 2\right.$ and $\sim 5^{\circ} \mathrm{C}$, respectively; Fig. 2) compared to $8^{\circ} \mathrm{C}$ in laboratory studies and $13^{\circ} \mathrm{C}$ in inter-population comparisons of temperature effects demographic effects less pronounced and/or more difficult to detect.

Hatch midpoint was the only hatch timing metric without a significant time trend during 1980 to 2011; all other hatch metrics had significant slopes (Table 2, Fig. 5). Hatch midpoint was strongly influenced by temperature during final maturation (Table 4, Fig. 6), which showed no significant time trend and had the lowest inter-annual variability of the temperature series (Fig. 2, Table 2). Thus at the level of temperature variation observed since 1980, the strongest effects have been on the timing of hatch initiation and completion. Warmer temperatures were associated with earlier initiation and later completion, thus the overall effect of warming to date appears to be an increase in the duration of the hatch period. However, the relationships involving hatch completion were noisy $\left(\mathrm{r}^{2}=0.13\right.$ for time trend, $\mathrm{r}^{2}=$ 0.15 for temperature), and fewer data were available to estimate completion dates, so the hatch completion results are somewhat tenuous.

A longer hatch period could provide compensatory reserve for the population by increasing the window of opportunity for larvae to co-occur with favorable conditions for survival and growth. Modeling studies predict reduced spread of developmental events with 
warmer temperature due to reduction of the right tail of the distribution (individuals in warmer water develop faster; Giminez 2011). This makes intuitive sense and has been shown empirically (e.g. Batten \& Mackas 2009); however, the contrary results with northern shrimp suggest that different or additional mechanisms may be involved. One possible explanation relates to the interaction between molting and reproduction in crustaceans. In laboratory studies with Pandalus borealis, warmer temperatures reduced the time between molts, but spawning was delayed at the warmest temperatures because an additional molt occurred before the ovaries were sufficiently mature to spawn. A nuptial molt and mating occurs immediately before egg extrusion in $P$. borealis, and thus shrimp that underwent an additional molt needed to complete that molt cycle before the nuptial molt, and reproduction was delayed (Stickney \& Perkins 1977, Shumway et al. 1985). This example illustrates the non-linear patterns that may emerge because of complex relationships between physiological processes, e.g. growth and reproduction, and implies that responses to continued temperature increase may be difficult to predict.

A recent analysis of long-term SST trends on the US northeast continental shelf identified a shift to a warmer state in the western Gulf of Maine around the millennium (Friedland \& Hare 2007). The shift was indicated by increased mean annual SST, increased spring warming rate, and decreased fall cooling rate; winter SST did not increase. In the present study, similar patterns were observed with more localized data, i.e. a steep increase $(10 \%)$ over time in SST during oogenesis (spring/summer) and no increase in SST during final maturation (winter). SST during oogenesis was $2.5^{\circ} \mathrm{C}$ higher on average during the most recent decade of this study (2002 to 2011) than during the first (1980 to 1989). Predicted warming for the Gulf of Maine and surrounding regions is 2 to $4^{\circ} \mathrm{C}$ by 2080 (Fogarty et al. 2007), suggesting that further changes in hatch timing may be expected.

Koeller et al. (2009) provided evidence that hatch timing in northern shrimp has evolved to optimize temporal overlap between larvae and their food supply. The midpoint of the shrimp hatch occurred near the onset of the spring phytoplankton bloom in most northern shrimp populations, despite widely differing latitudes and ecological conditions. Phenological shifts in hatch timing that are not matched by shifts in timing of phytoplankton blooms thus may be expected to have important consequences for shrimp populations if the offset in timing becomes too large.
Acknowledgements. The data for this study came from monitoring programs conducted over several decades by the Maine Department of Marine Resources and the US NOAA Northeast Fisheries Science Center. I gratefully acknowledge the many who have collected and archived the data over the years. I particularly appreciate the helpful input of D. Schick, M. Hunter, L. White, D. Mountain, and M. Taylor, and technical assistance from M. Teichberg.

\section{LITERATURE CITED}

Apollonio S, Stevenson D, Dunton E (1986) Effects of temperature on the biology of the northern shrimp, Pandalus borealis, in the Gulf of Maine. NOAA Tech Rep NMFS 42. National Marine Fisheries Service, Seattle, WA

Batten S, Mackas D (2009) Shortened duration of the annual Neocalanus plumchrus biomass peak in the Northeast Pacific. Mar Ecol Prog Ser 393:189-198

Bergström B (1991) Reproductive cycle and the effect of temperature on oogenesis of Pandalus borealis Krøyer, 1838. J Shellfish Res 10:327-331

Bergström B (2000) The biology of Pandalus. Adv Mar Biol 38:55-245

Brillon S, Lambert Y, Dodson J (2005) Egg survival, embryonic development, and larval characteristics of northern shrimp (Pandalus borealis) females subject to different temperature and feeding conditions. Mar Biol 147: 895-911

Clark SH (1989) State-federal northern shrimp survey. In: Azarovitz TR, McGurrin J, Seagraves R (eds) Proceedings of a workshop on bottom trawl surveys. ASMFC Special Report 17. Atlantic States Marine Fisheries Commission, Arlington, VA, p 27-29

Clark SH, Cadrin SX, Schick DF, Diodati PJ, Armstrong MP, McCarron D (2000) The Gulf of Maine northern shrimp (Pandalus borealis) fishery: a review of the record. J Northwest Atl Fish Sci 27:193-226

Dow R (1964) A comparison among selected marine species of an association between sea water temperature and relative abundance. J Cons Int Explor Mer 28:425-431

Edwards M, Richardson A (2004) Impact of climate change on marine pelagic phenology and trophic mismatch. Nature 430:881-884

Fogarty M, Incze L, Wahle R, Mountain D and others (2007) Potential climate change impacts on marine resources of the northeastern United States. Northeast Climate Impacts Assessment. Marine Sector Report. Union of Concerned Scientists, Cambridge, MA. Available at www. northeastclimateimpacts.org/pdf/miti/fogarty_et_al.pdf

Friedland K, Hare J (2007) Long-term trends and regime shifts in sea surface temperature on the continental shelf of the northeast United States. Cont Shelf Res 27: 2313-2328

> Gelin A, Crivelli A, Rosecchi E, Kerambrun P (2001) Can salinity changes affect reproductive success in the brown shrimp Crangon crangon? J Crustac Biol 21:905-911

Giminez L (2011) Exploring mechanisms linking temperature increase and larval phenology: the importance of variance effects. J Exp Mar Biol Ecol 400:227-235

Grosslein M (1969) Groundfish survey program of BCF at Woods Hole. Commer Fish Rev 31:22-35

> Haynes E, Wigley R (1969) Biology of the northern shrimp, Pandalus borealis, in the Gulf of Maine. Trans Am Fish Soc 98:60-76 
Holzwarth T, Mountain D (1990) Surface and bottom temperature distributions from the Northeast Fisheries Center spring and fall bottom trawl survey program, 1963-1987. Northeast Fisheries Center Laboratory Reference Document 90-03

Hunter M, Whitmore $\mathrm{K}$, Fischer J, Richards A, Waine M (2011) Assessment report for Gulf of Maine northern shrimp - 2011. Atlantic States Marine Fisheries Commission, Arlington, VA. Available at www.asmfc.org/ northernShrimp.htm

Koeller P, Fuentes-Yaco C, Platt T, Sathyendranath S and others (2009) Basin-scale coherence in phenology of shrimps and phytoplankton in the North Atlantic Ocean. Science 324:791-793

Link J, Idoine J (2009) Estimates of predator consumption of the northern shrimp Pandalus borealis with implications for estimates of population biomass in the Gulf of Maine. N Am J Fish Manag 29:1567-1583

McCrary J (1971) Sternal spines as a characteristic for differentiating between females of some Pandalidae. J Fish Res Board Can 28:98-100

Morgan S (1995) The timing of larval release. In: McEdward L (ed) Ecology of marine invertebrate larvae. CRC Press, New York, NY, p 157-191

> Mountain D, Jessen P (1987) Bottom waters of the Gulf of Maine, 1978-1983. J Mar Res 45:319-345

> Nagaraju GP (2011) Reproductive regulators in decapod crustaceans: an overview. J Exp Biol 214:3-16

Nunes P (1984) Reproductive and larval biology of northern shrimp, Pandalus borealis Krøyer, in relation to temperature. PhD dissertation, University of Alaska, Fairbanks, AL

Ohtomi J, Yamamoto S, Koshio S (1998) Ovarian maturation and spawning of the deep-water mud shrimp Solenocera melantho De Man, 1907 (Decapoda, Penaeoidea, Solenoceridae) in Kagoshima Bay, Southern Japan. Crustaceana (Leiden) 71:672-685

Parmesan C (2006) Ecological and evolutionary responses to recent climate change. Annu Rev Ecol Evol Syst 37: 637-669

Editorial responsibility: Steven Morgan, Bodega Bay, California, USA
Quackenbush L (1994) Lobster reproduction: a review. Crustaceana (Leiden) 67:82-94

Richards A, Fogarty M, Clark S, Schick D, Diodati P, O'Gorman B (1996) Relative influence of reproductive capacity and temperature on recruitment of Pandalus borealis in the Gulf of Maine. ICES CM 1996/K:13

Richards RA, Fogarty M, Mountain D, Taylor M (in press) Climate change and northern shrimp recruitment variability in the Gulf of Maine. Mar Ecol Prog Ser

$>$ Roberts S, Dixon C, Andreacchio L (2012) Temperature dependent larval duration and survival of the western king prawn, Penaeus (Melicertus) latisulcatus Kishinouye, from Spencer Gulf, South Australia. J Exp Mar Biol Ecol 411:14-22

SAS Institute (2003) SAS system for Linux ver. 9.1. SAS Institute, Cary, NC

Shumway S, Perkins H, Schick D, Stickney A (1985) Synopsis of biological data on the pink shrimp, Pandalus borealis Krøyer, 1838. NOAA Tech Rep NMFS 30. National Marine Fisheries Service, Seattle, WA

Smith T (2002) The Woods Hole bottom-trawl resource survey: development of fisheries-independent multispecies monitoring. ICES Mar Sci Symp 215:480-488

Stickney A, Perkins H (1977) Environmental physiology of commercial shrimp, Pandalus borealis. Completion Report, Project 3-202-R. Maine Department of Marine Resources, Boothbay Harbor, ME

Sydeman W, Bograd S (2009) Marine ecosystems, climate and phenology: introduction. Mar Ecol Prog Ser 393: 185-188

Webb JB, Eckert GL, Shirley TC, Tamone SL (2007) Changes in embryonic development and hatching in Chionoecetes opilio (snow crab) with variation in incubation temperature. Biol Bull (Woods Hole) 213: $67-75$

Wieland K (2005) Changes in recruitment, growth, and stock size of northern shrimp (Pandalus borealis) at West Greenland: temperature and density-dependent effects at released predation pressure. ICES J Mar Sci 62: 1454-1462

Submitted: September 12, 2011; Accepted: March 12, 2012 Proofs received from author(s): May 31, 2012 